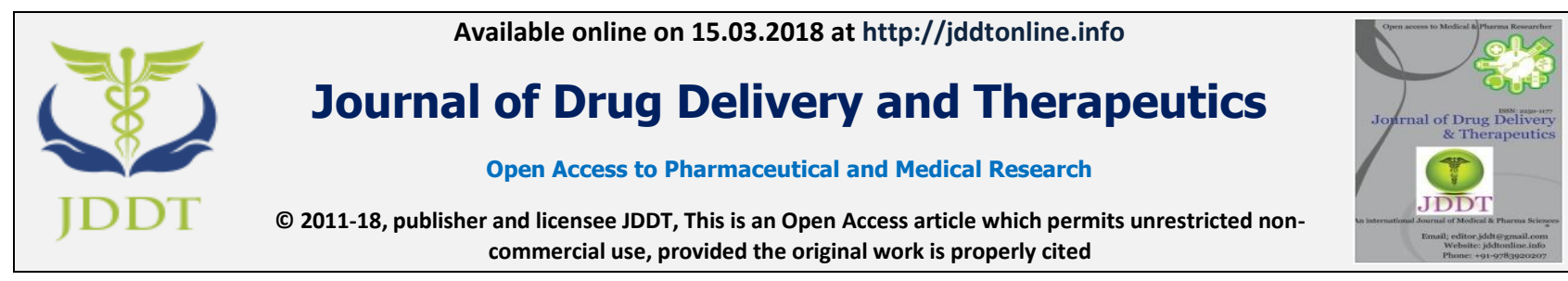

Open $\odot$ Access

Research Article

\title{
DEVELOPMENT AND IN VITRO EVALUATION OF AN ORAL FLOATING TABLET OF METRONIDAZOLE
}

\author{
Harshal Soni*, Chetan Ghulaxe, Surbhi Upadhyay, Sujit Pillai \\ GRY Institute of Pharmacy, Vidhya Vihar, Borawan (Khargone) - 451228, M.P., India
}

\begin{abstract}
The present study was undertaken with an aim to develop and evaluate gastroretentive floating tablets of Metronidazole that are designed to retain in the stomach for a long time and have developed as a drug delivery system for better eradication of Helicobacter Pylori in peptic ulcer diseases. The floating tablets of Metronidazole were made by direct compression method using polymer Carbopol 934 and sodium bicarbonate and citric acid as gas generating agent. The tablets were evaluated by pre and post compression parameters such as weight variation, thickness, friability, hardness, drug content, in-vitro buoyancy studies and in-vitro dissolution studies and results were within the limits. Hardness was found to be in the range of $7.6 \pm 0.27 \mathrm{~kg} / \mathrm{cm}^{2}$ to $7.9 \pm 0.35$ $\mathrm{kg} / \mathrm{cm}^{2}$, the percent friability was in the range of $0.48 \%$ to $0.52 \% \mathrm{w} / \mathrm{w}$ and the tablets showed $94 \%$ to $97 \%$ uniformity in drug content. The in-vitro dissolution studies were carried out in a USP type- II apparatus in $0.1 \mathrm{~N} \mathrm{HCl}$. The formulations were able to within 2-7 minutes and showed buoyancy $>12$ hrs. The drug-polymer ratio, viscosity grades of Carbopol 934 and gas generating agents were found to influence the release of drug and floating characteristics from the prepared floating drug delivery system of Metronidazole. Kinetically, among the 4 assessed models the release pattern of Metronidazole from the tablets fitted best to Higuchi's and zero order indicated that diffusion is the predominant mechanism controlling the drug release.
\end{abstract}

Keywords: Metronidazole, Floating tablets, Carbopol 934, Gastroretentive, Dissolution

Article Info: Received 10 Jan, 2018; Review Completed 5 March, 2018; Accepted 7 March, 2018; Available online 15 March, 2018

Cite this article as:

Soni H, Ghulaxe C, Upadhyay S, Pillai S, Development and in vitro evaluation of an oral floating tablet of metronidazole , Journal of Drug Delivery and Therapeutics. 2018; 8(2):83-86

DOI: http://dx.doi.org/10.22270/jddt.v8i2.1673

*Address for Correspondence: Harshal Soni, GRY Institute of Pharmacy, Vidhya Vihar, Borawan, Khargone-451228, M.P., India

\section{INTRODUCTION}

Controlled release dosage forms is the part of modified drug release dosage form which covers a wide range of prolonged action which provide continuous release of their active ingredients at predetermined rate and predetermined time $e^{1,2}$.

Since many drugs are well absorbed in the upper part of the gastrointestinal tract, such high variability may lead to non-uniform absorption and makes the bioavailability unpredictable. Hence a beneficial delivery system would be one which possesses the ability to control and prolong the gastric emptying time and can deliver drugs in higher concentrations to the absorption site (i.e. upper part of the small intestine) ${ }^{3,4}$.
Out of various controlled drug delivery systems floating drug delivery system utilizes principle of gastric retention time of the dosage forms at the stomach and upper part of the small intestine and suitable for the drug having site-specific absorption from the above sites and control the delivery of active ingredients. ${ }^{5,6}$.

Floating Drug Delivery System (FDDS) have a bulk density less than gastric fluids and so remain buoyant in the stomach without affecting the gastric emptying rate for a prolong period of time. While the system is floating on the gastric content, the drug is released slowly at the desired rate from the system. ${ }^{7,8,9}, 10$

Metronidazole is a synthetic antibacterial and antiprotozoal agent that belongs to the nitroimidazole class. It is indicated for the treatment of Helicobacter 
Pylori eradication therapy, as a part of multi drug regimen in peptic ulcer disease. It is usually taken two or three times a day. Administration of prolonged release floating tablet will result in prolonged retention of drug in the gastric fluid. Thus, resulting in complete dissolution of drug in extended period of time by enhancing the drug absorption and thereby reduces the dosing frequency of the drug in therapy ${ }^{7,11}$.

\section{MATERIALS AND METHODS}

Metronidazole was received as generous gift fron ZydusCadila, Ahemdabad India. Carbopol 934, microcrystalline cellulose, sodium starch glycolate, lactose were received from Loba Chemie pvt. Ltd. Mumbai. Citric acid received from S.D. Fine Chem. Limited, Mumbai. All other chemicals used were of analytical reagent grade, available commercially and used as such without further processing.

Methods: The excipients Carbopol 934 is used as polymer, sodium bicarbonate as effervescent mixture, lactose as diluent.

\section{Compression of tablets}

After pre compression evaluation the powder was directly compressed into tablet using punch tablet machine ${ }^{7,10}$.

\section{Evaluation of tablets:}

Hardness $^{7,10}$ :

The hardness was determined by Monsanto hardness tester. It is expressed in $\mathrm{kg} / \mathrm{cm}^{3}$.

Weight variation ${ }^{7,10}$ :

20 tablets were selected at random and weighed collectively and individually. From the collective weight average weight was calculated. Each tablet was then compared with the average weight.

\section{Thickness and diameter:}

The thickness and diameter of the tablets were determined by Vernier calliper. It is expressed in $\mathrm{mm}$.

\section{Friability $^{7,10}$ :}

Friability is determined by Roche friabilator. It is expressed in percentage. The friabilator was operated at $25 \mathrm{rpm}$ per min. for 4 minutes (100 revolutions). The tablets were initially weighed ( $\left.\mathrm{W}_{\text {INITIAL }}\right)$ and transferred into the friabilator. The tablets were than weighed $\left(\mathrm{W}_{\text {FINAL }}\right)$ again after operating the friabilator. The \% friability was calculated by the formula:

$$
\text { Percentage friability }=\mathrm{W}_{\text {INITIAL }}-\mathrm{W}_{\text {FINAL }} / \mathrm{W}_{\text {INITIAL }} * 100
$$

\section{Content uniformity:}

20 tablets of each formulation were weighed and powdered. The quantity equivalent to $100 \mathrm{mg}$ of metronidazole was transferred into a $100 \mathrm{ml}$ of volumetric flask and the volume was adjusted to $100 \mathrm{ml}$ with $0.1 \mathrm{~N} \mathrm{HCl}$. Further $1 \mathrm{ml}$ of the above solution was diluted to $100 \mathrm{ml}$ with $0.1 \mathrm{~N} \mathrm{HCl}$ and the absorbance of the solution was observed at $273 \mathrm{~nm}$.

\section{In- vitro buoyancy study:}

The in-vitro buoyancy was determined by floating lag time and total floating time. The tablets were placed in a $100 \mathrm{ml}$ beaker containing $0.1 \mathrm{~N} \mathrm{HCl}$. The time required for the tablet to rise to the surface and float was deyermined by floting lag time and the duration of the time the tablet contantly floats on the dissolution medium was noted as total floating time.

Dissolution study ${ }^{7,10}$ :

Release studies were performed in USP basket method. $900 \mathrm{ml}$ of $0.1 \mathrm{~N} \mathrm{HCl}$ was placed in the vessel and the medium was allowed to equilibrate to the temperature of $37+0.5^{\circ} \mathrm{C}$. Tablet was placed in the vessel and the paddle was operated at $75 \mathrm{rpm}$. At definite time intervals, $5 \mathrm{ml}$ of the fluid was withdrawn; filtered and again $5 \mathrm{ml}$ of the fluid was replaced. Suitable dilutions were done with the dissolution fluid and the samples were analyzed spectrophotometrically.

\section{Drug Release kinetics:}

To analyze the mechanism of drug release from the prepared formulations, the data obtained from in- vitro release studies were subjected to zero order, Higuchi's model and korsmeyer's model.

\section{RESULTS AND DISCUSSION}

\section{Formulation of floating tablet:}

In the present study, floating tablets of metronidazole were prepared by using Carbopol, microcrystalline cellulose (MCC) and sodium bicarbonate and citric acid as effervescent agent.

Floating tablets of metronidazole were developed to increase the gastric residence time of the drug, so that they can be retained in stomach for longer time resulting in controlled release of drug. A total number of three formulations (Table 1) were prepared by direct compression method.

Table 1: formulation tablet of floating tablet of Metronidazole

\begin{tabular}{|l|l|l|l|l|}
\hline S.N. & Ingredients(mg) & FM1 & FM2 & FM3 \\
\hline 1 & Metronidazole & 200 & 200 & 200 \\
\hline 2 & Carbopol & 100 & 150 & 200 \\
\hline 3 & MCC & 10 & 10 & 10 \\
\hline 4 & $\begin{array}{l}\text { Sodium starch } \\
\text { glycolate }\end{array}$ & 25 & 25 & 25 \\
\hline 5 & $\begin{array}{l}\text { Sodium } \\
\text { bicarbonate }\end{array}$ & 60 & 60 & 60 \\
\hline 6 & Citric acid & 15 & 15 & 15 \\
\hline 7 & Lactose & 90 & 40 & - \\
\hline
\end{tabular}

\section{Pre compression studies:}

The pre compression studies such as bulk density, tapped density, angle of repose, compressibility index were evaluated which were found to be within prescribed limits (Table 2). 
Table 2: Pre compression study data

\begin{tabular}{|l|l|l|l|}
\hline S.No. & Bulk density & Tapped density & Compressibility index $(\%)$ \\
\hline FM1 & 0.464 & 0.543 & 15.12 \\
\hline FM2 & 0.479 & 0.512 & 18.94 \\
\hline FM3 & 0.483 & 0.563 & 14.20 \\
\hline
\end{tabular}

\section{Post compression studies:}

The data obtained from physicochemical parameters such as hardness, friability, weight variation, drug content were in acceptable range (Table 3 ).

Table 3: Post compression studies

\begin{tabular}{|c|c|c|c|c|c|c|}
\hline S.No. & $\begin{array}{c}\text { Hardness } \\
\mathrm{kg} / \mathrm{cm}^{2}\end{array}$ & $\begin{array}{l}\text { Friability loss } \\
\text { in \% }\end{array}$ & $\begin{array}{c}\text { Weight variation } \\
(\mathrm{mg})\end{array}$ & $\begin{array}{c}\text { Uniformity drug } \\
\text { content }(\%)\end{array}$ & $\begin{array}{c}\text { Thickness } \\
(\mathbf{m m})\end{array}$ & $\begin{array}{c}\text { Diameter } \\
(\mathbf{m m})\end{array}$ \\
\hline FM1 & 6.6 & 0.6 & 498 & 96 & 4.6 & 10.6 \\
\hline FM2 & 8.2 & 0.5 & 480 & 94.5 & 5.3 & 10.4 \\
\hline FM3 & 7.4 & 0.7 & 478 & 95 & 5.8 & 10.5 \\
\hline
\end{tabular}

\section{In vitro buoyancy study:}

The in vitro buoyancy was determined by floating lag time. The tablets were placed in a $100 \mathrm{ml}$ beaker containing $0.1 \mathrm{~N} \mathrm{HCl}$. The time required by the tablet to rise to the surface and float was determined as floating lag time (Table 4).

Table 4: In vitro buoyancy study

\begin{tabular}{|l|l|}
\hline Formulation & Floating lag time (sec.) \\
\hline FM1 & 190 \\
\hline FM2 & 200 \\
\hline FM3 & 210 \\
\hline
\end{tabular}

In vitro dissolution study and release kinetics:

The release rate of metronidazole from floating tablets was determined using United States Pharmacopoeia (USP) 24 XXIV dissolution testing apparatus 2 (paddle method). The in vitro dissolution revealed that the formulation FM1 and FM2 released the drug faster as compared to formulation FM3. This is because a weak layer of gel around the tablet was formed in FM1 and FM2 formulation containing $100 \mathrm{mg}$ and $150 \mathrm{mg}$ that results in $85.28 \%$ and $80.25 \%$ of release of drug respectively. In case of FM3 formulation containing $200 \mathrm{mg}$ drug, a dense layer is formed that release that provides a delayed release of drug. Hence provides sustained release.

The curve fitting results of the in vitro release data of the formulations indicated that Higuchi model (Table 5) is the best fit to describe the release of drug from matrix floating tablet and the mechanism of drug release was diffusion.

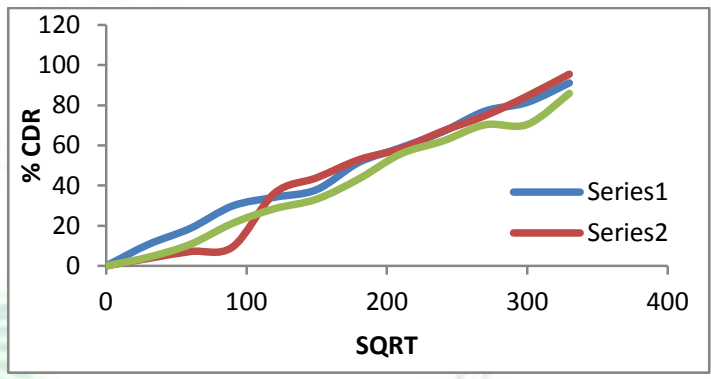

Figure 1: Cumulative drug release

Table 5: Release kinetics of different formulation

\begin{tabular}{|l|l|l|}
\hline Batches & Zero order & Higuchi model \\
\hline & $\mathrm{R}^{2}$ & $\mathrm{R}^{2}$ \\
\hline FM1 & 0.995 & 0.925 \\
\hline FM2 & 0.997 & 0.873 \\
\hline FM3 & 0.990 & 0.895 \\
\hline
\end{tabular}

\section{CONCLUSION}

This study discusses the preparation of floating tablets of metronidazole. The effervescent based floating drug delivery was a promising approach to achieve in vitro buoyancy. The addition of polymer Carbopol, HPMC and gas generating agent sodium bicarbonate and citric acid were essential to achieve in vitro buoyancy. The polymer composition affects the release of drug. It was also demonstrated that the release of drug can be changed by modifying the type and amount of polymer in the matrix tablets.

\section{Acknowledgements}

The author would like to thank Principal Dr. Sujit Pillai Sir, GRY Institute of Pharmacy, Borawan (khargone) for providing the facilities to carry out the research work. 


\section{REFERENCES}

1. Vyas S.P., Khar RK, "Textbook of Controlled drug delivery, concepts and advances", Vallabh Prakashan, New Delhi, first edition, 2002, P.P. 196-217.

2. Chein YW. Novel Drug Delivery Systems ed by Chein YW, Marcel Dekker, Inc., New York, USA 1992; 139-196.

3. Gurjar G., Bhowmick M., Rathi V., Rathi J. Design and evaluation of extended release cefuroxime axetil floating tablets with improved GI absorption. Journal of Drug Delivery and Therapeutics, 2017; 7(1):49-59. doi:10.22270/jddt.v7i1.1352

4. Keshari A., Tripathi D., Srivastava, A. Vishwas R. Formulation and evaluation of effervecent floating tablets of antidiabetic drug. Journal of Drug Delivery and Therapeutics, 2015; 5(6):43-55. doi:10.22270/jddt.v5i6.1176

5. Sahoo C., Rao S., Sudhakar M. Formulation and evaluation of controlled porosity osmotic pump tablets for zidovudine and lamivudine combination using fructose as osmogen. Journal of Drug Delivery and Therapeutics, 2017; 7(4):41-50. doi: $10.22270 /$ jddt.v7i4.1465

6. Momin S., Khan S., Ghadage D., Yadav A., Wagh A. Formulation and evaluation of bilayer tablets of propranolol hydrochloride. Journal of Drug Delivery and Therapeutics, 2017; 7(2):50-57. doi:10.22270/jddt.v7i2.1399
7. Amritha V., Kaur S , Pandey K, formulation and in vitro evaluation of floating tablets of hydroxypropylmethylcellulose K4M and carbopol using Metronidazole as model drug, International Journal of Pharmaceutical Science and Research, 2014; 2244-2249

8. Pant S, Badola A, Kothiyal P, A review on gastroretentive drug delivery system, Indian Journal of Pharmaceutical Science and Research. 2016; 4(2) :1-10

9. Dubey J, Verma N, Floating drug delivery system: A review, Indian Journal of Pharmaceutical Science and Research, 2013. 2893-2899

10. Yerikala R., Pudi V., Saravanakumar K., Vadhireddy S. Formulation and evaluation of floating drug delivery of cefotaxime using raft forming approach. Journal of Drug Delivery and Therapeutics, 2017; 7(4):110-119. doi:10.22270/jddt.v7i4.1473

11. Sharma A., Sharma P., Darwhekar G. Formulation and evaluation of bilayer tablet of metronidazole and dicyclomine hydrochloride for treatment of irritable bowel disease. Journal of Drug Delivery and Therapeutics, 2017; 7(7):56-58. doi:10.22270/jddt.v7i7.1586 